\title{
UNUSUAL MORPHOLOGY OF CALCIUM CARBONATE CONTROLLED BY AMINO ACIDS IN AGAROSE GEL
}

\author{
CHENG-LI YAO ${ }^{a^{*}}$, CHUN-XIA QI ${ }^{a}, J I N-M I A O ~ Z H U{ }^{a}, W A N G-H U A X U^{b}$ \\ ${ }^{a}$ Department of Chemistry, Hefei Teachers College, Hefei,Anhui 230061, China \\ ${ }^{b}$ Department of Chemistry, Anqing Teachers College, Anqing,Anhui 246011,China \\ (Received: December 21, 2009 - Accepted: March 23, 2010)
}

\begin{abstract}
The polar amino acid, such as aspartic acid (L-Asp) and arginine(L-Arg) are the primary active molecules of the glycoprotein on the organic/inorganic interface of biomineralized tissue. In this study, aspartic acid and arginine were used as the organic template in inducing the nucleation and growth of calcium carbonate. With the analysis of X-ray diffraction we investigated the relationship between amino acid concentration and the precipitation phase crystal structure of calcium carbonate. SEM was employed in the analysis of the morphological characteristic of the precipitation. To interpret the cause of the hierarchic structure was proposed from the view of the small biomolecules polarity that can control over the growth of the crystals and the aggregation of the micro crystals. The conclusion also provides a new material synthesize strategy.
\end{abstract}

Keywords: Calcium carbonate, biomineralization, aspartic acid, arginine, agarose gel

\section{INTRODUCTION}

Calcium carbonate $\left(\mathrm{CaCO}_{3}\right)$ is the most abundant mineral formed by organisms, followed by silica, calcium phosphate, and others. Biomineralization results in complex materials that are characterized by a remarkable level of molecular control of the particle size, structure and morphology, aggregation, and crystallographic orientation of the calcium carbonate phases. ${ }^{1,2}$ The variety of biomineralizates can be expressed by the fact that approximately 128000 species of molluscs exist ${ }^{3}$. The majority of them produce shells and capsules from $\mathrm{CaCO}_{3}$ having different sizes, shapes, and color patterns.

Many shells are constructed within frameworks that may be lamellar, columnar, or reticular. In each case, there are two important features of assembly. First, a relatively inert structural frame is built from insoluble macromolecules. ${ }^{4,5}$ Second, acidic proteins, such as L-Asp, are assembled on the hydrophobic scaffold. Mineralization takes place at the interface between the acidic proteins and the aqueous environment. Also, the oyster shell matrix contains $20-30 \mathrm{~mol} \%$ aspartate. ${ }^{2,6}$

Amino acids/protein-template synthesis of inorganic crystals and inorganic/organic hybrid structures has been highlighted in recent years. One of the most widely studied systems is $\mathrm{CaCO}_{3}$. Among amino acids, L-Asp particularly demands attention because some Asp-rich peptides are known to control the polymorphism and structure of $\mathrm{CaCO}_{3}$ during the process of biomineralization. ${ }^{7,8,9}$ Most previous papers have reported the effects of Asp on the calcite surface morphology during crystal growth and dissolution..$^{10,11,12}$

Agarose is a linear polysaccharide extracted from marine red algae, and consists of alternating 1,3-linked b-D-galactose and 1,4-linked 3,6-anhydro-aL-galactose. It forms a gel when a homogeneous solution is cooled to below the ordering temperature $\left(\sim 35^{\circ} \mathrm{C}\right)$ and an infinite three-dimensional network of agarose fibers develops; the melting of agarose gel occurs at a comparatively higher temperature $\left(\sim 85^{\circ} \mathrm{C}\right)$, leading to a setting-melting hysteresis behavior. ${ }^{13}$ Agarose gel is widely used in the food and pharmaceutical industries and as an important support for chromatography analysis. ${ }^{14}$

The aim of the present work is to investigate the effect of polar amino acid on the growth of carbonate crystals in the agarose gel/ amino acid system and to attempt to answer the following question: Does polar amino acid affect the nature, or the particle size of the calcium carbonate forming phases?

The structure of $\mathrm{CaCO}_{3}$ precipitation was investigated by a wide-angle $\mathrm{X}$-ray diffract meter (XRD). Scanning electron microscope (SEM) was employed to investigate morphologic features of the porous aggregate of the precipitation of $\mathrm{CaCO}_{3}$. Finally, a possible assumption was proposed for simulating organic control crystal growth and particle aggregation.

\section{MATERIALS AND METHODS}

\section{Material}

Agarose was purchased from Sigma. L-Asp and L-Arg were obtained from Institute of Biological Products of Shanghai (Shanghai, China). $\mathrm{CaCl}_{2}$ and $\mathrm{Na}_{2} \mathrm{CO}_{3}$ are all of analytical reagent grade. Deionized ultrapure water was used throughout the experiment.

\section{The synthesis of calcium carbonate}

In a typical synthesis, $\mathrm{CaCl}_{2}\left(100 \mathrm{~mL}, 0.05 \mathrm{~mol} \cdot \mathrm{L}^{-1}\right)$ solution was heated to $75 \sim 80{ }^{\circ} \mathrm{C}$ and $10 \%(\mathrm{w} / \mathrm{w})$ of agarose was added, which was further heated to $85 \sim 90^{\circ} \mathrm{C}$ to ensure dissolution of agarose, then adding various amounts of L-Asp (80 mg, $160 \mathrm{mg}, 320 \mathrm{mg}$ ) and L-Arg $(80 \mathrm{mg}, 160 \mathrm{mg}, 320 \mathrm{mg}$ ), respectively. The calcium chloride/agarose/ amino acid solution was poured into a culture dish and allowed to cool at the room temperature. The cooled agarose gel was cut into cubic pieces about $1 \mathrm{~cm}^{3}$ in volume, which were soaked in $\mathrm{Na}_{2} \mathrm{CO}_{3}\left(100 \mathrm{~mL}, 0.05 \mathrm{~mol} \cdot \mathrm{L}^{-1}\right)$ solution at $30^{\circ} \mathrm{C}$. After $48 \mathrm{~h}$ of incubation, the gel was rinsed in water to get rid of the residual inorganic salt. Finally, the resulting $\mathrm{CaCO}_{3}$ crystals were recovered by heating the gel containing $\mathrm{CaCO}_{3}$ crystals in hot water $\left(\sim 90^{\circ} \mathrm{C}\right)$ to dissolve agarose followed by washing and filtration. The preliminary experimental result showed that the short period of heating in hot water did not affect the crystal morphology considerably.

Characterization of crystal phase and morphology of precipitation

The sizes and morphologies of $\mathrm{CaCO}_{3}$ precipitates were characterized by using SEM on a DSM 940 A (Carl Zeiss, Jena) microscope. Calibration of $\mathrm{CaCO}_{3}$ pellets (in a proportion of $1 \%$ in $\mathrm{KBr}$ powder) was performed and recorded with a Niolet 870 Fourier Transform Infrared Spectrometer between $4000 \mathrm{~cm}^{-1}$ and $400 \mathrm{~cm}^{-1}$ with a resolution of $4 \mathrm{~cm}^{-1}$. The XRD measurements were made by an MAP18XAHF X-ray Diffractometer at a scanning rate of $4 \%$ min, using a monochromatized CuKa radiation $(\lambda=0.154 \mathrm{~nm})$.

\section{RESULTS AND DISCUSSION}

\section{SEM images}

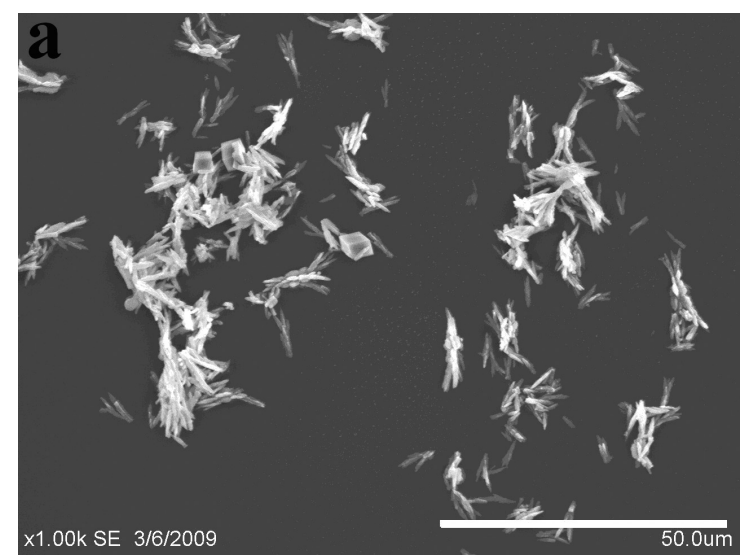



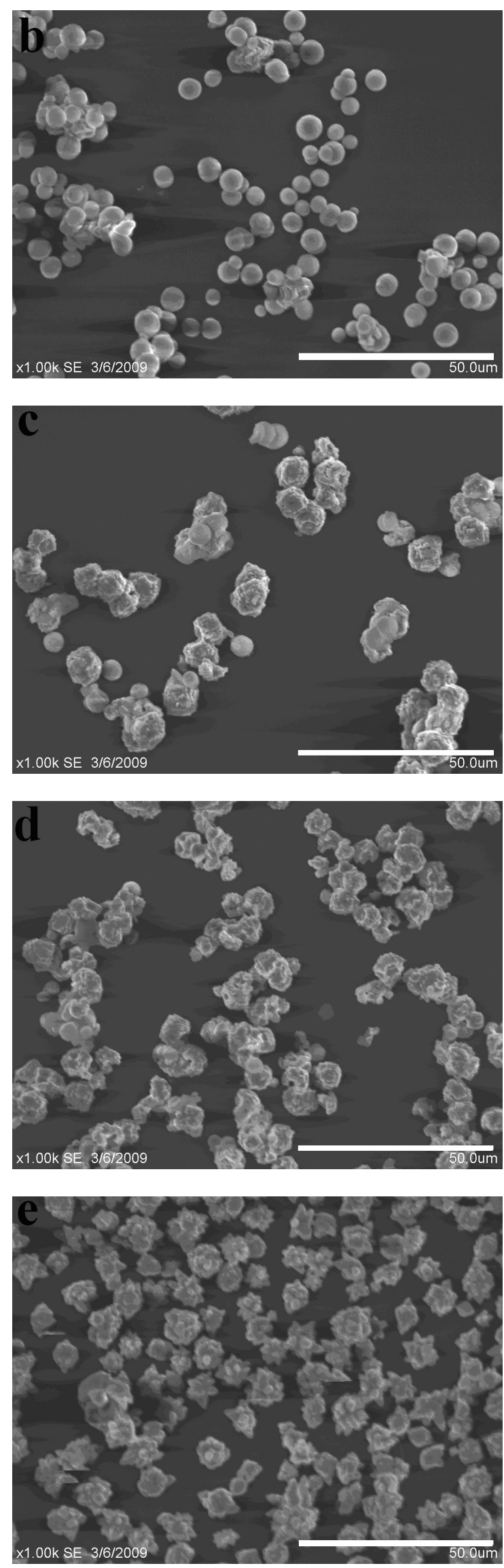
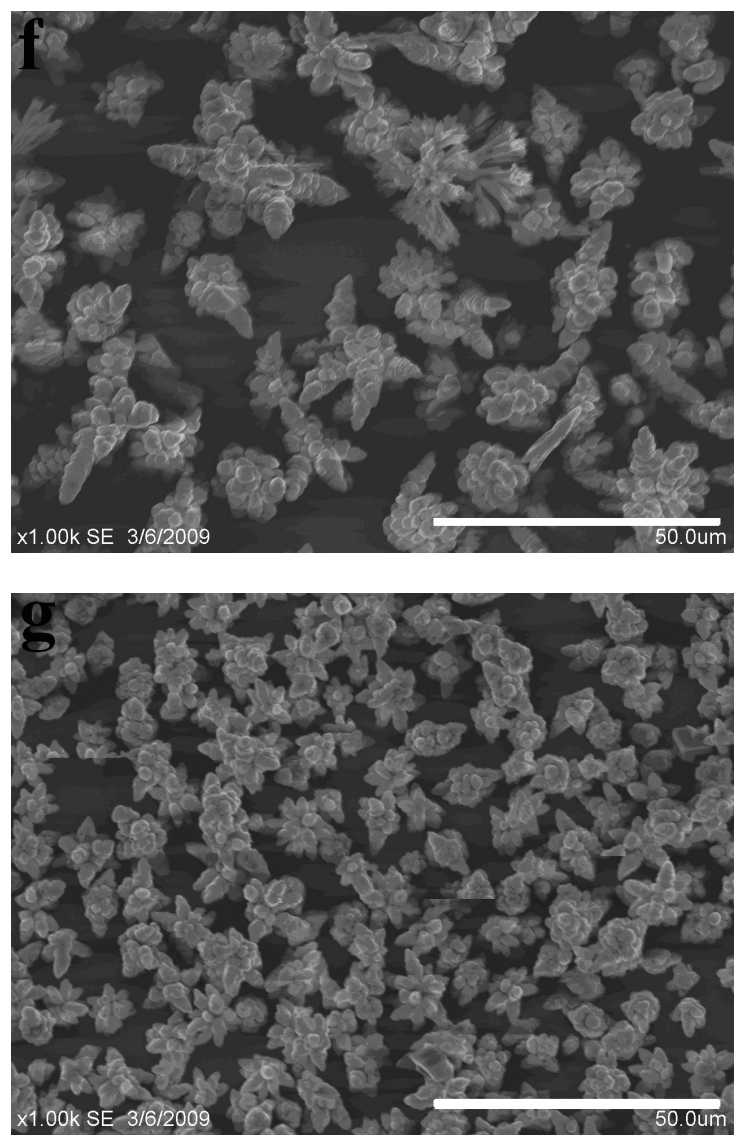

Figure 1: Morphologies of mineralized $\mathrm{CaCO}_{3}$ with different L-Asp/ L-Arg concentrations in the agarose system: (a) without L-Arg or L-Asp; (b) with L-Arg $0.8 \mathrm{mg} \cdot \mathrm{mL}^{-1}$; (c) with L-Arg $1.6 \mathrm{mg} / \mathrm{mL}$; (d) with L-Arg 3.2 $\mathrm{mg} \cdot \mathrm{mL}^{-1}$;(e) L-Asp $0.8 \mathrm{mg} \cdot \mathrm{mL}^{-1}$;(f) L-Asp $1.6 \mathrm{mg}^{\circ} \mathrm{mL}^{-1}$;(g) L-Asp $3.2 \mathrm{mg} \bullet \mathrm{mL}^{-1}$

Figure1a g showed SEM pictures of $\mathrm{CaCO}_{3}$ particles precipitated in $10 \%$ $(\mathrm{w} / \mathrm{w})$ of agarose and different concentrations amino acids. Figurela showed the tree branch-shaped crystals formed in the agarose without any amino acids. Well-dispersed spherical $\mathrm{CaCO}_{3}$ aggregate particles were produced in the system with L-Arg $\left(0.8 \mathrm{mg} \cdot \mathrm{mL}^{-1}\right)$ and the particle size was about5 $6 \mathrm{~mm}$ (as shown in Fig.1b).With the increase of $\mathrm{L}-\mathrm{Arg}$ concentration, spherical $\mathrm{CaCO}_{3}$ aggregate particles were still gained, but the amount became less. At the same time, there were many irregular particles formed which composed of little rhomboidal particles (Fig.1c).Surprisingly, when L-Arg concentration is $3.2 \mathrm{mg} \cdot \mathrm{mL}^{-1}$, the spherical $\mathrm{CaCO}_{3}$ aggregate particles disappeared (Fig.1d). Fig.1e-g showed SEM micrographs of $\mathrm{CaCO}_{3}$ particles obtained in the presence of $\mathrm{L}$-Asp with different concentrations $\left(0.8 \mathrm{mg} \cdot \mathrm{mL}^{-1} \square 1.6 \mathrm{mg} \cdot \mathrm{mL}^{-1} \square 3.2 \mathrm{mg} \cdot \mathrm{mL}^{-1}\right)$ in the agarose gel system, respectively. Similar to L-Arg, L-Asp had great influence on the morphology of $\mathrm{CaCO}_{3}$ particles and pine flower-like aggregate particles were obtained (as shown in Fig.1.e). However, with L-Asp concentrations from $1.6 \mathrm{mg} \cdot \mathrm{mL}^{-1}$ to $3.2 \mathrm{mg} \cdot \mathrm{mL}^{-1}$, unusual, maize cob-pine flower shaped $\mathrm{CaCO}_{3}$ aggregates radially aligned crystals were obtained (Fig.1f-g). These results indicate that L-Arg and L-Asp had significant influence on the morphology of $\mathrm{CaCO}_{3}$ in the agarose gel system.

\section{IR spectra and XRD}




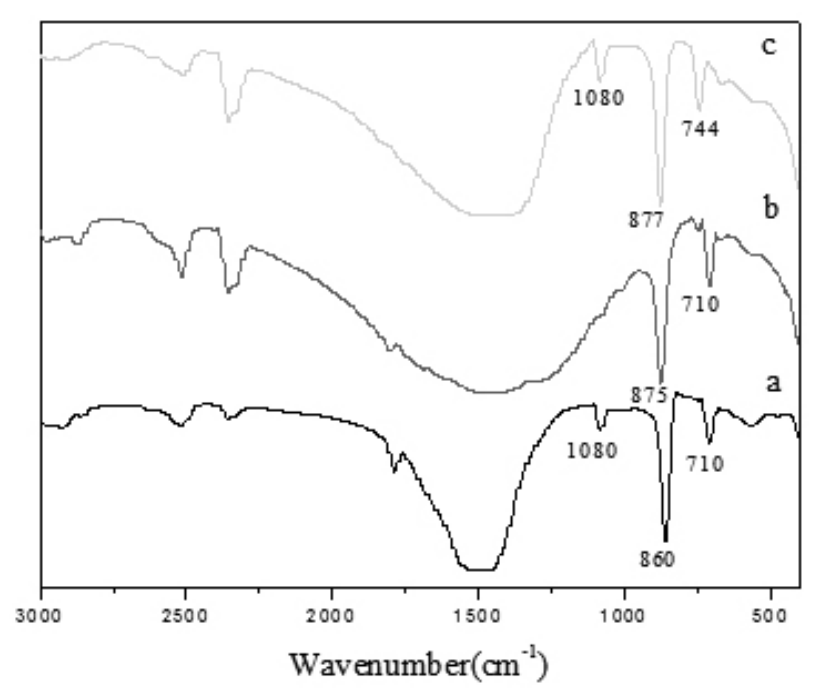

Figure 2: FT-IR spectra of $\mathrm{CaCO}_{3}$ with different L-Asp/ L-Arg concentrations in the agarose system:(a) without L-Arg or L-Asp;(b) with L-Arg $1.6 \mathrm{mg} \cdot \mathrm{mL}^{-1}$; (c) L-Asp $1.6 \mathrm{mg} \cdot \mathrm{mL}^{-1}$.

Infrared spectra of $\mathrm{CaCO}_{3}$ crystals produced in synthesized in the presence and absence of amino acid were presented in Fig.2. Fig.2a displayed the absorption peak of crystal at $860 \mathrm{~cm}^{-1}$ and $710 \mathrm{~cm}^{-1}$, while $860 \mathrm{~cm}^{-1}$ between 875 $\mathrm{cm}^{-1}$ and $856 \mathrm{~cm}^{-1}$ (the $\mathrm{CO}_{3}{ }^{2}$ out-of-plane deformation mode of the aragonite). ${ }^{15}$ The absorption peak of $710 \mathrm{~cm}^{-1}$ showed the calcite formed. It showed that the product was the mixture of calcite and aragonite. From Fig. $2 \mathrm{~b}$ we could see that FT-IR absorption bands at $875 \mathrm{~cm}^{-1}$ and $710 \mathrm{~cm}^{-1}$, in which $875 \mathrm{~cm}^{-1}$ is the $\mathrm{CO}_{3}{ }^{2-}$ out-of-plane deformation mode of the calcite, ${ }^{16}$ which indicated the presence of calcite. From the Fig.2c we also could find the absorption peak of $877 \mathrm{~cm}^{-1}, 744 \mathrm{~cm}^{-1}$, which indicted the vaterite formed .These results was confirmed by XRD.

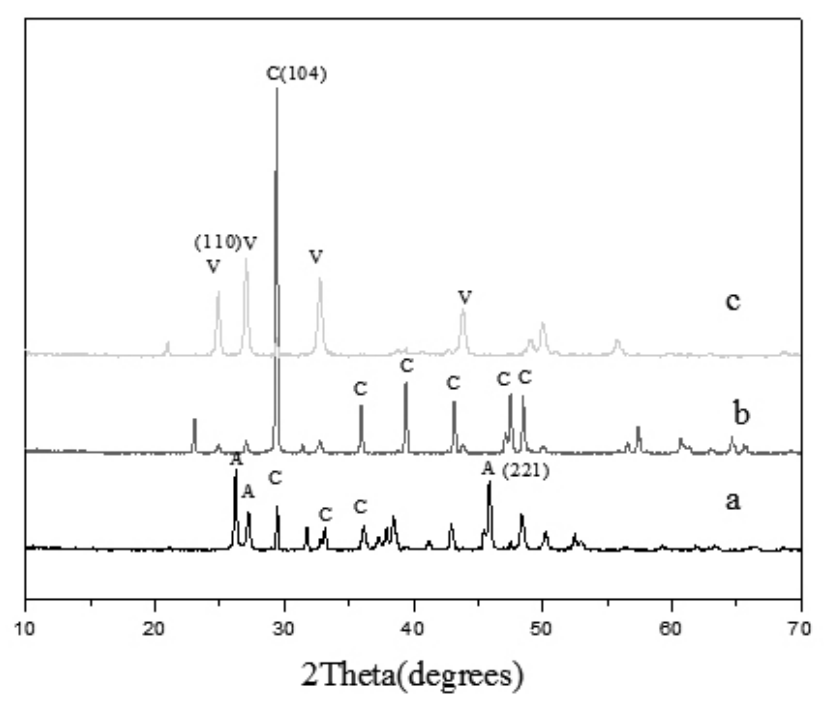

Figure 3: XRD patterns of of $\mathrm{CaCO}_{3}$ with different L-Asp/ L-Arg concentrations in the agarose system:(a) without L-Arg or L-Asp;(b) with $\mathrm{L}-$ Arg $1.6 \mathrm{mg} \cdot \mathrm{mL}^{-1}$; (c) L-Asp $1.6 \mathrm{mg} \cdot \mathrm{mL}^{-1}$.

Figure3a-c showed the XRD patterns of $\mathrm{CaCO}_{3}$ particles obtained in amino acid / agarose gel system. Using the reflection peaks at (104) plane for calcite,(221)plane for aragonite and (110) plane for vaterite, we can find that there are not only sharp calcite but aragonite reflections in figure $3 \mathrm{a}$, confirming that without any amino acid led to the formation of calcite and aragonite. While polar amino acid with different isoelectric point ( $\mathbf{p I}$ ) led to the formation of calcite or vaterite. As figure $3 \mathrm{~b}$ had shown, only the diffraction peaks from calcite appeared, this provides that it is easily to form calcite in the agarose gel system with L-Arg. Figure $3 \mathrm{c}$ had shown there only vaterite were formed in the agarose gel system with L-Asp.

The formation mechanism of $\mathrm{CaCO}_{3}$ crystal in the amino acids / agarose gel system

It is known that agarose is a neutral polysaccharide that mainly carries hydroxy functional groups. It has been documented that whereas the matrices of acid proteins including gelatin can exert significant effects on the $\mathrm{CaCO}_{3}$ crystallization, ${ }^{17,18,19}$ the matrices of polysaccharides such as chitosan/chitin usually do not solely exert direct effects on $\mathrm{CaCO}_{3}$ crystallization. ${ }^{20,21}$

There many research show that amino acids with different isoelectric point (pI) have different ability to induce the formation of $\mathrm{CaCO}_{3}$. Manoli, Kai and Tong ${ }^{12,22,23}$ found minerals adsorbing amino acids with charged $\mathrm{R}$ groups much more than with uncharged $\mathrm{R}$ groups. According their research we learned the uncharged polar amino acids in $\mathrm{CaCO}_{3}$ precipitates tend to stabilize the vaterite phase, and the vaterite content in $\mathrm{CaCO}_{3}$ precipitates is correlated to the concentration of amino acids in the precipitates. When $\mathbf{p I}$ of amino acids was higher than $\mathrm{pH}$ (7.0) of solution and positive charge was taken on its surface. It could attract $\mathrm{CO}_{3}^{-2}$ strongly, and result in the $\mathrm{CO}_{3}^{-2}$ ions being enriched; the higher supersaturation in the region was in favor of $\mathrm{CaCO}_{3}$ crystals to nucleate and grow. Electrostatic matching, structural and stereochemical complementarity made the amino acids offer nucleation sites for $\mathrm{CaCO}_{3}$ crystal, reduced interfacial energy and stabilized vaterite formation.

Therefore, it is expected that in the present case, agarose molecules do not directly affect the crystallization of $\mathrm{CaCO}_{3}$ and agarose gel just play a role of reaction media that control the diffusion process of ions in the media and hinder the crystal growth when the crystal size reaches the pore size of the agarose network. Considering that the pore size for the $1 \%$ agarose gel is around $140 \mathrm{~nm},{ }^{24}$ considerably smaller than the initial rhombohedral calcite crystals, the main role the agarose gel play on the $\mathrm{CaCO}_{3}$ crystallization could be the control on the diffusion process of reactant ions rather than the hindering of crystal growth. Therefore, a possible mechanism for the formation of the tree branch-shaped crystals is as follows: At first, $\mathrm{Ca}^{2+}$ ions were distributed uniformly in the agarose gel matrix. When $\mathrm{CO}_{3}^{-2}$ ions diffused into the gel, many small crystals formed suddenly, leading to a quick decrease of the reactant ion concentration nearby. With gradual diffusion of $\mathrm{CO}_{3}^{-2}$ ions into the gel, the nuclei grew the fastest since the agarose network causes a stagnant diffusion of ions to accumulate reactant ions for spatial reasons. With the prolongation of time, the tree branch-shaped crystals gradually extruded and radially extended(Figure 4).

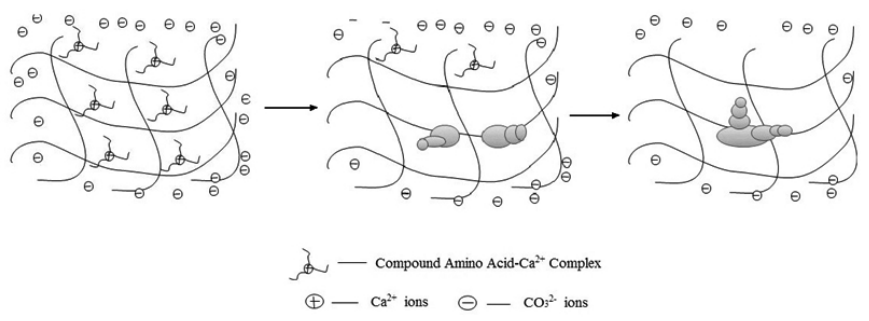

Figure 4: The possible formation mechanism of unusual morphology calcium carbonate.

With the addition of polar amino acid, the spherical $\square$ maize cob-pine flower shaped and other shaped $\mathrm{CaCO}_{3}$ particles were gained. The different shaped $\mathrm{CaCO}_{3}$ particles owed to the agarose gel matrix, but also amino acid with different isoelectric point. It is not difficult to find $\mathrm{CaCO}_{3}$ particles formed in the alkaline conditions in the experiments. The isoelectric point of L-Arg and L-Asp are $\mathrm{pI}=10.76$ and $\mathrm{pI}=2.97$, respectively. Irregular particles with little rhomboidal calcite particles formed in the L-Arg / agarose gel system and maize cob-pine flower shaped vaterite formed in the L-Asp / agarose gel system may be explained by the reasons below.

First, L-Arg possesses the R-helix conformation under alkaline conditions and coordinate with $\mathrm{Ca}^{2+},{ }^{25}$ which is a suitable template for $\mathrm{CaCO}_{3}$ mineralization. Second, $\mathrm{CaCO}_{3}$ is easier to deposit in an alkaline environment. Third, the agarose gel released $\mathrm{Ca}^{2+}$ slowly; hence the formation of calcium carbonate will towards easy and stable direction. However, alkaline condition is unsuitable for molecular conformation of L-Asp to fully stretch and the negative charges on its surface were surplus in the alkaline condition. It would attract $\mathrm{Ca}^{2+}$ strongly because of electrostatic interactions and offered bonding site. When $\mathrm{CO}_{3}^{2-}$ was added to the system, the $\mathrm{CaCO}_{3}$ nucleus was 
formed fast. However, the agarose gel afforded the $\mathrm{Ca}^{2+}$ slowly, which led to the accumulation of quasi-circular $\mathrm{CaCO}_{3}$ particles to all directions and the formation of maize cob-pine flower shaped $\mathrm{CaCO}_{3}$ at last.

\section{CONCLUSION}

In this study, the method of directly precipitation was used to obtain $\mathrm{CaCO}_{3}$ crystal. In these processes, additives such as L-Arg and L-Asp were added into the agarose gel to control the crystallization of $\mathrm{CaCO}_{3}$. The spherical $\square$ maize cob-pine flower shaped and other shaped $\mathrm{CaCO}_{3}$ particles were successfully produced in experiments. Different isoelectric point of amino acids will effect the morphology and structure of $\mathrm{CaCO}_{3}$. Amino acids such as L-Arg were helpful for the growth of calcite and L-Asp for vaterite. These results indicated that amino acid played essential importance role in the process of biomineralization of $\mathrm{CaCO}_{3}$.

\section{ACKNOWLEDGEMENTS}

Authors acknowledge the financial support provided by Natural Science Foundation of the Education Department of Anhui Province (No. KJ2009B239Z, No.KJ2008B173, No.KJ2009B112 ) for carrying out this work.

\section{REFERENCES}

1. Mann S.,Archibald D. D., Didymus J. M.,Douglas T.,Heywood B. R.,Meldrum F. C. and Reeves N. J.,Science 261,1286, (1993).

2. Mann S.,Nature 365, 499, (1993).

3. Krampitz G and Graser G., Angew. Chem. 27,1145,(1988).

4. Manoli F., Koutsopoulos S. and Dalas E.,J. Cryst. Growth 182, 116, (1997).

5. Manoli F.and Dalas E., J. Cryst. Growth 204, 369, (1999).

6. Borman de Jong A. H., Huizinga M., Kok D. J., Westbroek P.and Bosh L., Eur. J. Biochem. 129, 179, (1982).
7. A. Wierzbicki, C. S. Sikes, J. D. Madura and B. Drake, Calcif. Tissue Int. 54, 133, (1994)

8. I. Sarashina and K. Endo, Am. Mineral. 83,1510, (1998).

9. B.-A. Gotliv, N. Kessler, J. L. Sumerel, D. E. Morse, N.Tuross, L. Addadi and S. Weiner, ChemBioChem 6, 304, (2005).

10. H. H. Teng and P. M. Dove,Am. Mineral. 82, 878, (1997).

11. C. A.Orme, A. Noy, A. Wierzbicki, M. T. McBride, M. Grantham, H. H.Teng, P. M. Dove and J. J. DeYoreo, Nature 411, 775,(2001).

12. H. Tong,W. Ma, L. Wang, P. Wan, J. Hu and L. Cao, Biomaterials 25.3923, (2004).

13. V. Normand, D. L. Lootens, E. Amici, K. P. Plucknett and P. Aymard,Biomacromolecules 1,730, (2000).

14. C. I. D. Bica, R. Borsali, E. Geissler and C. Rochas,Macromolecules 34,5275, (2001).

15. E. Beniash, J. Aizenberg, L. Addadi and S. Weiner, Proc. R. Soc. London Ser.B 264,461, (1997).

16. I.M. Weiss, N. Tuross, L. Addiadi, S. Weiner, J. Exp. Zool. 293, 478, (2002).

17. G. Falini, S. Fermani, M. Gazzano and A. Ripamonti, Chem. Eur. J. 3, 1807, (1997).

18. G. Falini, S. Fermani, M. Gazzano and A. Ripamonti, J.Chem. Soc., Dalton Trans. 21, 3983,(2000).

19. O. Grassmann, G. Müller and P. Löbmann, Chem. Mater. 14, 4530, (2002)

20. T. Kato, Adv.Mater. 12, 1543, (2000).

21. Dong Yang, Limin Qi and Jiming Ma, Chem. Commun. 10, 1180,(2003)

22. F. Manoli, J. Kanakis, P. Malkaj, E. Dalas, J. Crystal Growth 236,363 , (2002).

23. A. Kai, K. Fujikawa, T. Miki, Jpn. J. Appl. Phys. 41, 439, (2002)

24. C. I. D. Bica, R. Borsali, E. Geissler and C. Rochas, Macromolecules 34, 5275, (2001).

25. Shibata A, amamoto M, Yamashita T, Chiou J.-S., Kamaya H.and Ueda, I, Biochemistry 31, 5728, (1992). 